Pacific Journal of Mathematic 


\title{
GENERALIZED BOL FUNCTIONAL EQUATION
}

\author{
V. D. Belousov and P. L. KanNapPan
}

Each identity in a group or in a quasigroup induces a generalized identity (functional equation) in a class of quasigroups. Generalized associativity, generalized bisymmetry and generalized distributivity are examples of such generalized identities. From the left Bol identity

$$
x(y(x z))=(x(y x)) z
$$

on a quasigroup, we obtain a generalized Bol identity on a class of quasigroups :

$$
A_{1}\left(x, A_{2}\left(y, A_{3}(x, z)\right)\right)=A_{4}\left(A_{5}\left(x, A_{6}(y, x)\right), z\right),
$$

where the $A_{i}$ 's are quasigroup operations on a set $Q$. The general solution of this generalized Bol functional equation is obtained by reducing it to another functional equation

$$
P(x, y+S(x, z))=P(x, y+\alpha(x))+z
$$

where $P$ and $S$ are quasigroup operations on $Q$ and $\alpha(x)=S(x, 0)$. If the operations in the last functional equation are considered on real numbers (or groups), then the solution of this equation is obtained.

One of the most important identities considered in the theory of quasigroups is Bol identity. A loop $Q(\cdot)$ isc alled a left Bol loop [2] if the following identity

$$
x(y(x z))=(x(y x)) z,
$$

holds for every $x, y, z \in Q$. The identity (1) is called the left Bol identity. The right Bol identity is defined analogously

$$
((z x) y) x=z((x y) x) \text {. }
$$

For more information of algebraic properties of Bol loops, see for example [4]. If a loop is both a right and a left Bol, then it is a Moufang loop, i.e. one of the following Moufang identities are satisfied :

$$
\begin{aligned}
& x(y(x z))=((x y) x) z, \\
& ((z x) y) x=z(x(y x)) .
\end{aligned}
$$

It is easily seen that (3) is a particular case of $(2)$; if $Q(\cdot)$ satisfies the elasticity law $(x y) x=x(y x)$, then (1) implies (3). On the other hand the left Moufang identity (3) does not imply (1), see for example [3]. 
Each identity in an universal algebra defines a generalized identity which is obtained from the given identity by replacing operations of the same arity (number of variables) by different operations of the same arity. Generalized associativity $A_{1}\left(A_{2}(x, y), z\right)=A_{3}\left(x, A_{4}(y, z)\right)$, generalized bisymmetry $A_{1}\left(A_{2}(x, y), A_{3}(u, v)\right)=A_{4}\left(A_{5}(x, u), A_{6}(y, v)\right)$, generalized distributivity $A_{1}\left(x, A_{2}(y, z)\right)=A_{3}\left(A_{4}(x, y), A_{5}(x, z)\right) \quad$ are examples of such generalized identities. These identities considered as functional equations were studied by many authors, for references see [1].

To the left Bol identity (1) corresponds the generalized Bol (left identity):

$$
A_{1}\left(x, A_{2}\left(y, A_{3}(x, z)\right)\right)=A_{4}\left(A_{5}\left(x, A_{6}(y, x)\right), z\right) .
$$

The corresponding identity for the right Bol identity is

$$
B_{1}\left(B_{2}\left(B_{3}(z, x), y\right), x\right)=B_{4}\left(z, B_{5}\left(B_{6}(x, y), x\right)\right) .
$$

Of course all operations $A_{i}, B_{j}(i, j=1,2, \cdots, 6)$ in (5) and (6) are defined on the same set $Q$.

We shall consider the equations (5) and (6) on quasigroups, that is, we assume that all $A_{i}$ and $B_{j}$ are quasigroups (quasigroup operations). In the next sections, we reduce the equation (s) to a simpler one containing two quasigroups and one loop, and we give a full solution of this equation under some suppositions. For the definitions and results on quasigroups and loops, see for example [2], [3].

2. We shall use the following notations. Let $A$ be a binary operation defined on the set $Q$. We denote the translations of $A$ by

$$
L_{A}(a) x=A(a, x), \quad R_{A}(a, x)=A(x, a) .
$$

If $A$ is one of the operations $A_{i}(i=1,2, \cdots, 6)$ from (5) then we shall write $L_{i}(a)$ instead of $L_{A_{i}}(a)$ and moreover, if $a$ is a fixed element $k$ of $Q$, then we shall write $L_{i}$ instead of $L_{i}(k)$. Similar notations are used for right translations.

Let 0 be a fixed element of the set $Q$. We denote by $L_{A}(0)=L$, $R_{A}(0)=R$ and

$$
x+y=A\left(R^{-1} x, L^{-1} y\right) .
$$

Then $Q\left(+{ }_{A}\right)$ is a loop [3] with the neutral element $A(0,0)=0_{A}$.

Let all the operations in (5) be quasigroup oparations. Then $L_{i}$ 's and $R_{i}$ 's are permutations of $Q$. If $x=k$ in (5), then from (7), we have

$$
L_{1} A_{2}\left(y, L_{3} z\right)=A_{4}\left(L_{5} R_{6} y, z\right),
$$


that is,

$$
A_{4}(y, z)=L_{1} A_{2}\left(R_{6}^{-1} L_{5}^{-1} y, L_{3} z\right) .
$$

Using (5) and (9), we have

$$
A_{1}\left(x, A_{2}\left(y, A_{3}(x, z)\right)\right)=L_{1} A_{2}\left(\dot{R}_{6}^{-1} L_{5}^{-1} A_{5}\left(x, A_{6}(y, x), L_{3} z\right) .\right.
$$

With $z=k$ in (10), we get using (7),

$$
A_{1}\left(x, A_{2}\left(y, R_{3} x\right)\right)=L_{1} R_{2}^{\prime} R_{6}^{-1} L_{5}^{-1} A_{5}\left(x, A_{6}(y, x)\right),
$$

where $R_{2}^{\prime}=R_{2}\left(L_{3} k\right)$. From (10) and (11), we obtain

$$
L_{1}^{-1} A_{1}\left(x, A_{2}\left(y, A_{3}(x, z)\right)\right)=A_{2}\left(R_{2}^{\prime-1} L_{1}^{-1} A_{1}\left(x, A_{2}\left(y, R_{3} x\right)\right), L_{3} z\right) .
$$

Let

$$
C_{1}(x, y)=L_{1}^{-1} A_{1}(x, y) .
$$

Now (12) and (13) yield,

$$
C_{1}\left(x, A_{2}\left(y, A_{3}(x, z)\right)\right)=A_{2}\left(R_{2}^{\prime-1} C_{1}\left(x, A_{2}\left(y, R_{3} x\right)\right), L_{3} z\right),
$$

that is,

(14) $C_{1}\left(x, A_{2}\left(R_{2}^{\prime-1} y, R_{3} R_{3}^{-1} A_{3}(x, z)\right)\right)=A_{2}\left(R_{2}^{\prime-1} C_{1}\left(x, A_{2}\left(R_{2}^{\prime-1} y, R_{3} x\right)\right), L_{3} z\right)$.

Let

$$
C_{2}(x, y)=A_{2}\left(R_{2}^{\prime-1} x, R_{3} y\right), \quad C_{3}(x, y)=R_{3}^{-1} A_{3}\left(x, L_{3}^{-1} R_{3} y\right) .
$$

With the help of (15), (14) can be rewritten as,

$$
C_{1}\left(x, C_{2}\left(y, C_{3}\left(x, R_{3}^{-1} L_{3} z\right)\right)\right)=C_{2}\left(C_{1}\left(x, C_{2}(y, x)\right), R_{3}^{-1} L_{3} z\right),
$$

that is,

$$
C_{1}\left(x, C_{2}\left(y, C_{3}(x, z)\right)\right)=C_{2}\left(C_{1}\left(x, C_{2}(y, x)\right), z\right) \text {. }
$$

From (13) and (15), it follows that $C_{1}, C_{2}$ and $C_{3}$ are quasigroup operations on $Q$, since $L_{1}, L_{3}, R_{3}$ and $R_{2}^{\prime}$ are permutations of $Q$.

As every quasigroup is isotopic to a loop [3], we can assume that $C_{2}$ is isotopic to a loop, that is, $C_{2}$ satisfies

$$
C_{2}(x, y)=R x+L y, \quad \text { where } R \text { and } L \text { are as in (8) . }
$$

Then $Q(+)$ is a loop. By (17), (16) becomes,

$$
C_{1}\left(x, R y+L C_{3}(x, z)\right)=R C_{1}(x, R y+L x)+L z,
$$

that is,

$$
C_{1}\left(x, y+L C_{3}(x, z)\right)=R C_{1}(x, y+L x)+L z .
$$


Now define

$$
P(x, y)=C_{1}(x, y), \quad S(x, y)=L C_{3}\left(x, L^{-1} y\right) .
$$

Evidently $P$ and $S$ are quasigroup operations on $Q$. Using (19), we obtain from (18),

$$
P(x, y+S(x, L z))=R P(x, y+L x)+L z,
$$

that is,

$$
P(x, y+S(x, z))=R P(x, y+L x)+z .
$$

Putting $z=0$ in (20), we have

$$
P(x, y+S(x, 0))=R P(x, y+L x),
$$

and thus, we get

$$
P(x, y+S(x, z))=P(x, y+\alpha(x))+z,
$$

where $\alpha(x)=S(x, 0)$.

Hence from (9), (13), (15), (17) and (19), results

$$
\left\{\begin{array}{l}
A_{1}(x, y)=L_{1} C_{1}(x, y)=L_{1} P(x, y) \\
A_{2}(x, y)=C_{2}\left(R_{2}^{\prime} x, R_{3}^{-1} y\right)=R R_{2}^{\prime} x+L R_{3}^{-1} y \\
A_{3}(x, y)=R_{3} C_{3}\left(x, R_{3}^{-1} L_{3} y\right)=R_{3} L^{-1} S\left(x, L R_{3}^{-1} L_{3} y\right) \\
A_{4}(x, y)=L_{1} A_{2}\left(R_{6}^{-1} L_{5}^{-1} x, L_{3} y\right)=L_{1}\left(R R_{2}^{\prime} L_{5}^{-1} x+L R_{3}^{-1} L_{3} y\right),
\end{array}\right.
$$

where $P$ and $S$ satisfy (21).

With $L_{1}=\phi, R R_{2}^{\prime}=\lambda, L R_{3}^{-1}=\mu, L_{3}=\psi, R_{2}^{\prime} R_{6}^{-1} L_{5}^{-1}=\theta$, (22) can be rewritten as,

$$
\left\{\begin{array}{l}
A_{1}(x, y)=\phi P(x, y) \\
A_{2}(x, y)=\lambda x+\mu y \\
A_{3}(x, y)=\mu^{-1} S\left(x, \mu \psi^{\prime} y\right) \\
A_{4}(x, y)=\phi(R \theta x+\mu \psi y)
\end{array}\right.
$$

where $P$ and $S$ satisfy (21) and $\phi, \lambda, \mu, \psi, R$ and $\theta$ are permutations on $Q$.

From (11) and (23), we obtain

$$
\begin{aligned}
A_{1}\left(x, A_{2}\left(y, R_{3} x\right)\right) & =\phi P\left(x, \lambda y+\mu R_{3} x\right) \\
& =\phi P(x, \lambda y+L x) \\
\text { also } & =\phi \theta A_{5}\left(x, A_{6}(y, x)\right),
\end{aligned}
$$

thus

$$
A_{5}\left(x, A_{6}(y, x)\right)=\theta^{-1} P(x, \lambda y+L x) .
$$


Thus we have proved a part of the following,

Theorem 1. Let $Q$ be an arbitrary set. Let $A_{i}(i=1, \cdots 6)$ be quasigroup operations satisfying (5). Then all the solutions of the functional equation (5) are given by (23) and (24) where $\phi, \lambda, \mu, \psi$, $R, \alpha, \theta$ and $L$ are arbitrary permutations of $Q$, the loop operation + and the quasigroup operations $P$ and $S$ satisfy (21). Conversely the $A_{i}$ 's $(i=1,2, \cdots, 6)$ given by $(23)$ and $(24)$, where $P$ and $S$ satisfy (21), satisfy the generalized Bol equation (5).

By a straight forward computation, it is easy to verify the converse part.

REMARK 1. The solutions of the right Bol functional equation (6), can be obtained from (5), by replacing all the $B_{i}$ 's in (6) by the $D_{i}$ 's where

$$
D_{i}(x, y)=B_{i}(y, x) \text {. }
$$

REMARK 2. The generalized Moufang functional equation

$$
A_{1}\left(x, A_{2}\left(y, A_{3}(x, z)\right)\right)=A_{4}\left(A_{5}\left(A_{6}(x, y), x\right), z\right)
$$

can also be reduced to (21). In that by the same computation, we obtain (12), from which (16) and finally (21). All the solutions are similar to (23). Only difference is (24), where instead of (24), we get

$$
A_{5}\left(A_{6}(x, y), x\right)=\theta^{-1} P(x, \lambda y+L x) \text {. }
$$

3. As we have seen in $\S 2$, the solution of the Bol functional equation (5) is reduced to that of (21). Let us now consider this equation (5) on the set of real numbers $\mathbb{R}$; and let us suppose that $Q(+)$ is the additive group of real numbers. So, we have to consider (21) on $\mathbf{R}$.

Letting $S(x, z)=t$ in (21), we get, using $S$ as a quasigroup operation

$$
P(x, y+t)=P(x, y+\alpha(x))+S^{-1}(x, t), x, y, t \in \mathbb{R},
$$

where $\alpha(x)=S(x, 0)$. Thus, we obtain

$$
\lambda_{x}(y+t)=\mu_{x}(y)+\nu_{x}(t), \quad \text { for all } y, t \in \mathbf{R},
$$

where

$$
\lambda_{x}(u)=P(x, u), \quad \mu_{x}(u)=P(x, u+\alpha(x)), \quad \nu_{x}(u)=S^{-1}(x, u) .
$$

Equation (25) is the well known Pexider equation. Hence there exists an additive function $A_{x}$ on $\mathbf{R}$ satisfying 


$$
A_{x}(u+v)=A_{x}(u)+A_{x}(v),
$$

for all $u, v \in \mathbf{R}$, such that

$$
\left\{\begin{array}{l}
\lambda_{x}(u)=C(x)+A_{x}(u), \\
\mu_{x}(u)=b(x)+A_{x}(u), \\
\nu_{x}(u)=d(x)+A_{x}(u),
\end{array}\right.
$$

where $b(x), c(x), d(x)$ are constants depending on $x$ with $c(x)=$ $b(x)+d(x)$. With the notation

$$
F(x, u)=A_{x}(u),
$$

we obtain from (26), (28) and (29),

$$
\begin{gathered}
P(x, u)=c(x)+F(x, u), \\
S^{-1}(x, u)=d(x)+F(x, u),
\end{gathered}
$$

where $F$ is additive in the second variable for each fixed $x$. From (30), we see that $F$ is a right quasigroup, that is,

$$
F(a, x)=b \text {, has a unique solution for all } a, b \text {. }
$$

If in (31), we put $S^{-1}(x, u)=w$, then we have

$$
\begin{aligned}
d(x)+F(x, u) & =w, \\
S(x, w) & =u .
\end{aligned}
$$

Thus,

$$
S(x, d(x)+F(x, u))=u .
$$

Since $S(x, 0)=\alpha(x)$, we have $S^{-1}(x, \alpha(x))=0$. Thus, from (31) with $u=\alpha(x)$, we get $d(x)=F(x,-\alpha(x))$, using $F$ additive in the second variable. Hence (33) becomes

$$
S(x, F(x, u-\alpha(x)))=u,
$$

that is

$$
S(x, F(x, y))=y+\alpha(x),
$$

from which follows using (32),

$$
S(x, y)=\alpha(x)+F^{-1}(x, y)
$$

Therefore, we have proved the following:

THEOREM 2. Let $Q(+)$ be the additive group of real numbers. Then the general solution of (21) is given by (30) and (34) where 
$F$ is an arbitrary right quasigroup which is additive in the second variable and $c(x)$ and $\alpha(x)$ are arbitrary functions. Conversely if $P$ and $S$ are given by (30) and (34) with $F$ additive in the second variable, then (21) holds.

The converse part can be obtained by easy computation.

REMARK 3. In order for $P$ and $S$ to be quasigroups, we need the following conditions on $C(x)$ and $\alpha(x) ; C(x)+F(x, a)=b$ and $\alpha(x)+F^{-1}(x, a)=b$ should have unique solutions for given $a$ and $b$. But if we require only $P$ and $S$ to be right quasigroups, then we do not need these conditions and the solution of (21) is given by (30) and (34) for arbitrary $C(x)$ and $\alpha(x)$.

REMark 4. If we take $P$ to be monotonic in the second variable, then from (27), (29) and (30), we see that $A_{x}(u)$ is continuous and, for $A_{x} \not \equiv 0, A_{x}(u)=l(x) u$, for arbitrary $l(x)$. Hence $P(x, u)=C(x)+$ $l(x) u$ and $S(x, u)=\alpha(x)+u / l(x)$.

REMARK 5. Instead of the additive group of real numbers, we can take an arbitrary group and consider the Pexider type equation on this group. The general solution of (21) is given by (28) and hence by (30) and (34). But the constant functions $c(x), b(x)$ and $d(x)$ in (28) should be written in a proper way [5].

\section{BIBLIOGRAPHY}

1. J. Aczel, Theory of Functional Equations and Its Applications, Academic Press, 1966.

2. V. D. Belousov, Foundations of Theory of Quasigroups and Loops (Russ), Moscow, 1967.

3. R. H. Bruck, A survey of Binary Systems, Springer-Verlag, 1958.

4. A. D. Robinson, Bol loops, Tran. Amer. Math. Soc. 123 (1966), 341-354.

5. E. Vincze, Über eine verallgemeinerung der Pexiderschen funktional-gleichungen, Studia Univ., Babes-Bolyai, 1 (1962), 103-105.

Received February, 5, 1970. This research is supported by the National Research Council of Canada Grant No. A-7183.

Moldavian ACAdemy of Sciences, U.S.S.R.

UNIVERSITY OF WATERLOO, WATERLOO 



\section{PACIFIC JOURNAL OF MATHEMATICS}

\section{EDITORS}

\author{
H. SAMELSON \\ Stanford University \\ Stanford, California 94305

\section{Richard Pierce} \\ University of Washington \\ Seattle, Washington 98105
}

J. DugundJI

Department of Mathematics

University of Southern California

Los Angeles, California 90007

RichaRd ARENS

University of California

Los Angeles, California 90024

\section{ASSOCIATE EDITORS}
E. F. BECKENBACH
B. H. NeUMANN
F. WOLE
K. YoshidA

\section{SUPPORTING INSTITUTIONS}

\author{
UNIVERSITY OF BRITISH COLUMBIA \\ CALIFORNIA INSTITUTE OF TECHNOLOGY \\ UNIVERSITY OF CALIFORNIA \\ MONTANA STATE UNIVERSITY \\ UNIVERSITY OF NEVADA \\ NEW MEXICO STATE UNIVERSITY \\ OREGON STATE UNIVERSITY \\ UNIVERSITY OF OREGON \\ OSAKA UNIVERSITY \\ UNIVERSITY OF SOUTHERN CALIFORNIA
}

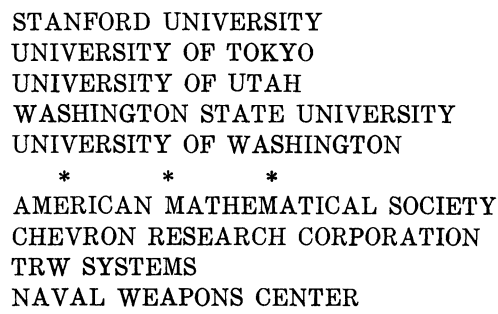

The Supporting Institutions listed above contribute to the cost of publication of this Journal, but they are not owners or publishers and have no responsibility for its content or policies.

Mathematical papers intended for publication in the Pacific Journal of Mathematics should be in typed form or offset-reproduced, (not dittoed), double spaced with large margins. Underline Greek letters in red, German in green, and script in blue. The first paragraph or two must be capable of being used separately as a synopsis of the entire paper. The editorial "we" must not be used in the synopsis, and items of the bibliography should not be cited there unless absolutely necessary, in which case they must be identified by author and Journal, rather than by item number. Manuscripts, in duplicate if possible, may be sent to any one of the four editors. Please classify according to the scheme of Math. Rev. Index to Vol. 39. All other communications to the editors should be addressed to the managing editor, Richard Arens, University of California, Los Angeles, California, 90024.

50 reprints are provided free for each article; additional copies may be obtained at cost in multiples of 50 .

The Pacific Journal of Mathematics is published monthly. Effective with Volume 16 the price per volume (3 numbers) is $\$ 8.00$; single issues, $\$ 3.00$. Special price for current issues to individual faculty members of supporting institutions and to individual members of the American Mathematical Society: $\$ 4.00$ per volume; single issues $\$ 1.50$. Back numbers are available.

Subscriptions, orders for back numbers, and changes of address should be sent to Pacific Journal of Mathematics, 103 Highland Boulevard, Berkeley, California, 94708.

PUBLISHED BY PACIFIC JOURNAL OF MATHEMATICS, A NON-PROFIT CORPORATION

Printed at Kokusai Bunken Insatsusha (International Academic Printing Co., Ltd.), 7-17, Fuj̣imi 2-chome, Chiyoda-ku, Tokyo, Japan. 


\section{Pacific Journal of Mathematics}

\section{Vol. 35, No. $2 \quad$ October, 1970}

Valentin Danilovich Belousov and Palaniappan L. Kannappan, Generalized Bol functional equation .................................... 259

Charles Morgan Biles, Gelfand and Wallman-type compactifications ........... 267

Louis Harvey Blake, A generalization of martingales and two consequent convergence theorems .................................... 279

Dennis K. Burke, On p-spaces and $w \Delta$-spaces..................... 285

John Ben Butler, Jr., Almost smooth perturbations of self-adjoint operators . . . . . . 297

Michael James Cambern, Isomorphisms of $C_{0}(Y)$ onto $C(X) \ldots \ldots \ldots \ldots \ldots . \ldots 307$

David Edwin Cook, A conditionally compact point set with noncompact closure ... 313

Timothy Edwin Cramer, Countable Boolean algebras as subalgebras and homomorphs .........................................

John R. Edwards and Stanley G. Wayment, A v-integral representation for linear operators on spaces of continuous functions with values in topological vector spaces.............................................

Mary Rodriguez Embry, Similarities involving normal operators on Hilbert

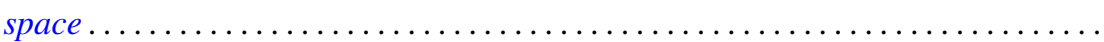

Lynn Harry Erbe, Oscillation theorems for second order linear differential

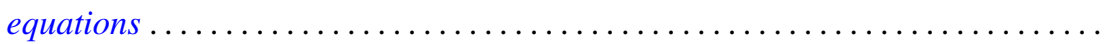

William James Firey, Local behaviour of area functions of convex bodies .......... Joe Wayne Fisher, The primary decomposition theory for modules ..............

Gerald Seymour Garfinkel, Generic splitting algebras for Pic ..................

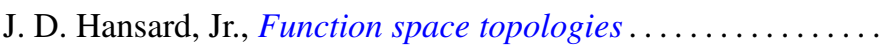

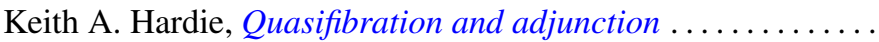

G. Hochschild, Coverings of pro-affine algebraic groups ...........

Gerald L. Itzkowitz, On nets of contractive maps in uniform spaces ..

381

389

399

417

Melven Robert Krom and Myren Laurance Krom, Groups with free nonabelian subgroups....................................

James Robert Kuttler, Upper and lower bounds for eigenvalues by finite differences ......................................

Dany Leviatan, A new approach to representation theory for convolution transforms . . .

Richard Beech Mansfield, Perfect subsets of definable sets of real numbers ...

Brenda MacGibbon, A necessary and sufficient condition for the embedding of a

Lindelof space in a Hausdorff $\mathscr{H} \sigma$ space ..................

David G. Mead and B. D. McLemore, Ritt's question on the Wronskian ....

Edward Yoshio Mikami, Focal points in a control problem .....

Paul G. Miller, Characterizing the distributions of three independent n-dimensional random variables, $X_{1}, X_{2}, X_{3}$, having analytic characteristic functions by the joint distribution of $\left(X_{1}+X_{3}, X_{2}+X_{3}\right)$. . .

P. Rosenthal, On the Bergman integral operator for an elliptic partial differential equation with a singular coefficient....

Douglas B. Smith, On the number of finitely generated $O$-group 